\title{
PENGALAMAN KEIKUTSERTAAN DALAM KELOMPOK PENDUKUNG IBU UNTUK MENINGKATKAN PEMBERIAN ASI EKSLUSIF
}

\author{
Primastika Supadmi ${ }^{1, *}$, Wenny Artanty Nisman², Elsi Dwi Hapsari ${ }^{2}$ \\ ${ }^{1}$ Program Studi Ilmu Keperawatan Fakultas Kedokteran, Kesehatan Masyarakat, dan Keperawatan, \\ Universitas Gadjah Mada, Jl. Farmako Sekip Utara, Yogyakarta, 55281 Indonesia \\ ${ }^{2}$ Departemen Keperawatan Anak dan Maternitas, Fakultas Kedokteran, \\ Kesehatan Masyarakat, dan Keperawatan, \\ Universitas Gadjah Mada, Jl. Farmako Sekip Utara, Yogyakarta, 55281 Indonesia \\ *) E-mail: Primastika.supadmi@gmail.com
}

\begin{abstract}
ABSTRAK
Latar Belakang: Keefektifan KP ibu dalam meningkatkan pemberian ASI eksklusif telah terbukti dalam banyak penelitian akan tetapi pelaksanaan KP ibu belum berjalan secara optimal di Indonesia. Sebanyak 22 KP ibu telah dibentuk di Kecamatan Pakem sejak tahun 2011, namun saat ini hanya beberapa KP ibu yang masih aktif. Hal ini dapat disebabkan oleh berbagai faktor. Faktor yang berasal dari peserta KP ibu masih belum banyak diteliti. Tujuan: Mengeksplorasi pengalaman keikutsertaan peserta dalam Kelompok Pendukung Ibu. Metode: Penelitian kualitatif dengan pendekatan fenomenologi. Partisipan penelitian berjumlah tujuh partisipan terdiri atas empat partisipan dari KP ibu aktif dan tiga partisipan dari KP ibu tidak aktif. Pengambilan data dilakukan pada bulan September-November 2015 menggunakan teknik wawancara mendalam semi struktur dan analisis data menggunakan metode Colaizzi. Hasil: Ditemukan enam tema yang terbagi atas dua tema di KP ibu aktif dan empat tema di KP ibu tidak aktif. Dua tema di KP ibu aktif yakni 1) menambah pengetahuan, memberikan solusi masalah anak, kesenangan saat berkumpul dan bernyanyi serta kesempatan berbagi pengalaman dan 2) pelaksanaan KP ibu belum berjalan optimal disebabkan faktor dari motivator, peserta, dan lingkungan. Empat tema pada KP ibu tidak aktif yakni 3) menambah pengetahuan, memberikan kesempatan berbagi pengalaman, dan mengubah keputusan untuk menyusui, 4) sulitnya mengumpulkan peserta, 5) peserta kurang berminat mengikuti kegiatan KP ibu, dan 6) tidak banyak memberikan pengetahuan baru pada peserta. Kesimpulan: Secara umum, kegiatan KP ibu memberikan banyak manfaat bagi peserta. Kendala pelaksanaan kegiatan KP ibu berasal dari faktor motivator, peserta, dan lingkungan.
\end{abstract}

Kata Kunci: Kelompok Pendukung Ibu, ASI eksklusif

\section{Experience of Participation in a Mother Support Group to Increase Exclusive Breastfeeding}

\section{ABSTRACT}

Background: The effectiveness of mother support group (MSG) in increasing exclusive breastfeeding has been proven in many studies but the implementation of the MSG has not run optimally in Indonesia. A total of 22 MSGs had been formed in Pakem since 2011, but currently only a few MSG is still active. It can be caused by various factors. Factor derived from the participants still have not been studied. Objective: To explore the participation experience of participants in the MSG. Methods: Qualitative research with phenomenological approach. The study participants were seven participants consisted of four participants from active MSG and three participants from inactive MSG. Data were collected in September-November 2015 using a semi-structured interview technique and indepth. Data analysis using Colaizzi method. Results: Six themes were found in this study, divided into two themes in active MSG and four themes in inactive MSG. Two themes in the active MSG are 1) to increase knowledge, provide solutions for children's problem, pleasure gather and sing as well as the opportunity to share experiences and 2) the implementation of the MSG is not optimal due to factors of motivators, participants, and the environment. Four themes at inactive MSG are 3) to increase knowledge, provide an opportunity to share experiences, and change the decision to breastfeed, 4) the difficulty of 
gathering participants, 5) participants are less interested in following the MSG activities, and 6) does not give much new knowledge to the participants. Conclusion: In general, MSG activity provides many benefits to the participants. Constraints of MSG implementation came from factors of motivator, participants, and the environment.

Keywords: Mother Support Group, Exclusive Breastfeeding

\section{LATAR BELAKANG}

Keefektifan program Kelompok Pendukung lbu (KP-lbu) dalam meningkatkan pemberian ASI eksklusif telah terbukti pada percobaan ilmiah yang dilakukan di 14 negara dengan melibatkan 29.385 pasang ibu-anak (Britton, dkk, 2007). Berdasarkan data Puskesmas Pakem, Daerah Istimewa Yogyakarta, terjadi peningkatan angka cakupan ASI eksklusif semenjak dibentuk KP-Ibu. Angka cakupan pemberian ASI eksklusif di Kecamatan Pakem menjadi yang tertinggi dibandingkan kecamatan lainnya dan mencapai target nasional yakni sebesar 82,69 persen. Kesuksesan ini seyogyanya dipertahankan dengan pemberdayaan KPIbu akan tetapi studi pendahuluan pada bulan Maret 2015 justru menunjukkan hanya satu dari $10 \mathrm{KP}$-lbu yang masih aktif mengadakan kegiatan rutin.

Banyak faktor yang dapat menyebabkan KP-Ibu menjadi tidak aktif, salah satunya adalah peserta. Oleh karena itu, perlu dieksplorasi bagaimana pelaksanaan kegiatan KP-Ibu berdasarkan pengalaman peserta saat mengikuti kegiatan KP-Ibu baik dari KP-Ibu yang masih aktif dan KP-lbu yang sudah tidak aktif untuk mengetahui permasalahan yang terjadi sekaligus sebagai bahan evaluasi.

\section{METODE}

Penelitian kualitatif dengan pendekatan fenomenologi. Penelitian ini telah dilaksanakan di wilayah Daerah Istimewa Yogyakarta khususnya di wilayah kerja Puskesmas Pakem pada bulan SeptemberNovember 2015.

Partisipan dalam penelitian ini berjumlah tujuh orang yang berasal dari dua kelompok, yakni empat partisipan dari KP-lbu yang masih aktif dan tiga partisipan dari KP-Ibu yang sudah tidak aktif yang telah memenuhi kriteria eksklusi dan inklusi. Kriteria inklusi untuk partisipan dari KP ibu yang masih aktif meliputi: 1) Tinggal di wilayah Sleman, Daerah Istimewa Yogyakarta, 2) Peserta KP Ibu yang masih aktif di wilayah kerja Puskesmas Pakem, 3) Aktif mengikuti kegiatan KP Ibu, 4) Mampu berkomunikasi menggunakan Bahasa Indonesia; dan 5) Bersedia menjadi partisipan penelitian.

Sedangkan kriteria untuk kelompok KP Ibu yang sudah tidak aktif meliputi: 1) Tinggal di wilayah Sleman, Daerah Istimewa Yogyakarta, 2) Berasal dari peserta KP ibu di wilayah kerja Puskesmas Pakem yang sekarang sudah tidak aktif, 3) Mengetahui jalannya kegiatan KP ibu, 4) Mampu berkomunikasi menggunakan Bahasa Indonesia, 5) Bersedia menjadi partisipan penelitian.

Keseluruhan partisipan mengikuti kriteria eksklusi, yaitu: 1) Tidak ingin melanjutkan penelitian, 2) Tidak direkomendasikan oleh motivator, 3) Ibu dengan bayi yang memiliki penyakit kronis, 4) Ingatan/memori mengenai keikutsertaan dalam KP ibu sudah banyak yang hilang (lupa).

Instrumen penelitian ini adalah peneliti sendiri. Teknik pengambilan data menggunakan metode wawancara mendalam semi terstruktur. Beberapa pertanyaan yang diajukan antara lain:

1) Bagaimana perasaan ibu saat mengikuti kegiatan di KP ibu?,

2) Apa saja yang ibu dapatkan selama mengikuti kegiatan tersebut?,

3) Dapatkah ibu ceritakan pengalaman 
ibu yang menarik selama mengikuti kegiatan KP ibu?,

4) Dapatkan ibu ceritakan pengalaman ibu yang tidak menyenangkan yang ibu alami selama mengikuti kegiatan KP ibu?

5) Bagaimana peran motivator di KP ibu?

6) Bagaimana proses diskusi di setiap pertemuan?

Wawancara dilakukan di masing-masing rumah partisipan. Setiap kali wawancara berlangsung sekitar 15 menit. Validasi data dilakukan dengan triangulasi sumber pada motivator KP-lbu dan pembina KP-lbu dan triangulasi metode dengan cara observasi.
Analisis hasil penelitian menggunakan metode Colaizzi (1978) yang dikutip Emzir (2010). Penelitian ini telah mendapat Ethics Committee Approval dengan No. Ref. KE/ FK/936/EC/2015 pada tanggal 29 Juli 2015.

\section{HASIL}

\section{Karakteristik Partisipan}

Partisipan berjumlah tujuh orang merupakan peserta KP-lbu yang berusia diantara 25-49 tahun dengan rincian karakteristik seperti terlihat pada Tabel 1. Mayoritas partisipan penelitian merupakan ibu rumah tangga dengan tingkat pendidikan terakhir menengah ke atas.

Tabel 1. Karakteristik Partisipan

\begin{tabular}{lccccc}
\hline Responden & Umur & Pekerjaan & $\begin{array}{c}\text { Pendidikan } \\
\text { terakhir }\end{array}$ & $\begin{array}{c}\text { Jumlah } \\
\text { Anak }\end{array}$ & $\begin{array}{c}\text { Usia anak } \\
\text { terakhir }\end{array}$ \\
\hline KP-Ibu Aktif & & & & & \\
Partisipan 1 & 33 tahun & IRT & SMK & 3 & 3 bulan \\
Partisipan 2 & 35 tahun & IRT & S1 & 3 & 10 bulan \\
Partisipan 3 & 49 tahun & IRT & SMP & 0 & 1,5 bulan (cucu) \\
Partisipan 4 & 34 tahun & IRT & SMA & 2 & 17 bulan \\
KP-Ibu Tidak Aktif & & & & \\
Partisipan 5 & 24 tahun & IRT + jasa catering & SMK & 1 & 4 tahun \\
Partisipan 6 & 36 tahun & IRT + jasa laundry & SMK & 2 & 3,5 tahun \\
Partisipan 7 & 35 tahun & Freelance & SMA & 2 & 2,5 tahun \\
\hline
\end{tabular}

Sumber: Data Primer

Pada KP-Ibu yang masih aktif dijumpai usia anak kurang dari 2 tahun, sedangkan pada KP-lbu yang tidak aktif usia anak sudah lebih dari 2 tahun. Sasaran/peserta KP ibu merupakan ibu hamil atau ibu menyusui yang mempunyai bayi usia 0-6 bulan. Sesuai panduan dari Kementerian Kesehatan RI (2012), jika sasaran utama kurang dari enam orang, maka sasaran KP-lbu dapat ditambah dengan ibu yang mempunyai anak usia 6 bulan hingga 2 tahun.

\section{Gambaran Pengalaman Keikutsertaan Peserta Kelompok Pendukung Ibu}

Secara keseluruhan pada penelitian ini ditemukan enam tema. Dua tema ditemukan pada KP-Ibu masih aktif yakni tema 1) Menambah pengetahuan, memberikan solusi masalah anak, kesenangan saat berkumpul dan bernyanyi dengan peserta lain serta kesempatan berbagi pengalaman, dan tema 2) Pelaksanaan KP-Ibu belum berjalan optimal disebabkan faktor dari 
motivator, peserta, dan lingkungan. Empat tema lainnya yakni tema 3) Menambah pengetahuan, memberikan kesempatan berbagi pengalaman, dan mengubah keputusan untuk menyusui, tema 4) Sulitnya mengumpulkan peserta, tema 5) Peserta kurang berminat untuk mengikuti kegiatan KP-Ibu, dan tema 6) Tidak banyak memberikan pengetahuan baru pada peserta. Tema 1 dan 3 menunjukkan kesamaan isi tentang manfaat yang diperoleh peserta di KP-Ibu.

\section{a. Keikutsertaan Peserta di Kegiatan KP- Ibu Memberikan Manfaat}

Keikutsertaan ibu dalam KP-lbu memberikan banyak manfaat diantaranya menambah pengetahuan, memberikan solusi masalah anak, kesempatan berbagi pengalaman, kesenangan saat berkumpul dan bernyanyi dengan peserta lain serta mengubah keputusan menyusui. Hal ini seperti yang diungkapkan oleh partisipan sebagai berikut:

"Kalau saya secara jadi ibu-ibu jadi lebih tahu. Ya seneng dapat informasi. Kita dapat tambahan pengetahuan langsung dari sesama ibu." (partisipan 7)

"Kalau aku ya senang bisa kumpul sama bisa berbagi misalnya aku ada yang enggak tahu, kan ada ibu lain yang tahu." (partisipan 1)

\section{b. Pelaksanaan KP-Ibu Belum Berjalan Optimal disebabkan Faktor dari Motivator, Peserta, dan Lingkungan}

1) Faktor yang berasal dari Motivator

Motivator menjadi salah satu faktor yang berpengaruh pada belum optimalnya pelaksanaan kegiatan KPIbu. Adanya keterbatasan pengetahuan motivator diungkapkan oleh partisipan menjadi kendala dalam memandu jalannya diskusi dan penyampaian informasi seperti berikut:
"Tapi kan motivatornya pengetahuannya kurang kalau enggak ditambah dari Puskesmas. Jadi ya terbatas" (partisipan 3)

Keterbatasan jumlah motivator juga diungkapkan partisipan menjadi penyebab belum optimalnya pelaksanaan KP-Ibu. Berikut salah satu pernyataan partisipan:

"Sebenarnya KP-lbu itu kan bertiga, cuma yang satu anaknya lagi sakit di rumah sakit harus bolak balik. Nah yang satu keluar, jadi tinggal satu." (partisipan 3)

2) Faktor yang berasal dari Peserta

Berdasarkan hasil wawancara, kegiatan di KP-lbu dianggap kurang menarik sehingga memunculkan rasa bosan pada peserta. Berikut salah satu ungkapan partisipan:

"Ya wajar to Mbak nek kadang bosen. Wong acaranya juga cuma gitu, nyanyi, sharing terus pulang. Apalagi nek anaknya rewel kan jadi kesusu pulang." (partisipan 4)

Adanya peserta yang kurang kooperatif dan pasif menyebabkan pelaksanaan KP-Ibu tidak berjalan optimal. Hal ini terlihat dari pernyataan partisipan sebagai berikut:

"Ya aktif Mbak, tapi paling satu dua yang tanya. Yang lainnya dengerin Mbak." (partisipan 2)

Anak rewel dan adanya kesibukan lain jadi kendala menghadiri KP-lbu seperti ungkapan partisipan berikut:

"Tapi ya pesertanya enggak ajeg kalau ada peserta yang terburu-buru ya enggak ikut, anaknya nangis ya pulang". (partisipan 4)

3) Faktor yang berasal dari Lingkungan

Waktu pelaksanaan KP-Ibu yang bersamaan dengan posyandu menjadikan peserta kurang bisa fokus. Berikut 
ini pernyataan partisipan:

"Kayaknya ya biasa-biasa aja Mbak wong kurang bisa fokus, soalnya kegiatannya disambi sama Posyandu." (partisipan 4)

\section{c. Sulitnya Mengumpulkan Peserta}

Hasil penelitian terhadap partisipan dari KP-Ibu tidak aktif menunjukkan terhambatnya pelaksanaan KP-lbu disebabkan oleh sulitnya mengumpulkan peserta. Walaupun pelaksanaan KP-Ibu sudah diadakan bersamaan dengan posyandu, peserta atau ibu-ibu kadang datang tidak dalam satu waktu bersamaan sehingga menyulitkan motivator seperti ungkapan partisipan berikut:

"Kalau datangnya satu-satu kan susah Mbak. Satu nimbang anaknya rewel pulang. Kalau enggak rewel ya ibunya punya kegiatan di rumah. Jadinya kan susah ngumpulinnya." (partisipan 6)

Persoalan lain yang juga menghambat pelaksanaan kegiatan KP ibu ketika Pembina KP ibu datang terlambat dan peserta sudah banyak yang pulang. Berikut ungkapan partisipan:

"Kadang ibu-ibu kalau udah kelamaan nunggu pada kemrungsung Mbak, selak arep ngopo, jadi pada pulang. Puskesmasnya datang, pesertanya sudah tinggal dikit." (partisipan 5)

Kesibukan ibu juga menyebabkan sulitnya menentukan jadwal yang tepat. Penetapan waktu pelaksanaan di luar waktu posyandu juga masih menemui kendala dalam mengumpulkan peserta seperti dalam ungkapan partisipan berikut:

"Kayaknya ibu-ibu disini yang kurang respon Mbak. Soalnya dulu motivatornya juga sudah pernah ngajakin ayo besok tanggal ini kumpulan KP-Ibu di rumah sapa, tapi ya pada enggak berangkat. Yang punya balita itu banyak yang enggak berangkat. Kalau pas posyandu kan keslamur sama kegiatan lain to jadi istilahnya enggak fokus to, jadi yuk diganti tanggal berapa gitu, tapi ya diundang enggak pada datang." (partisipan 5)

\section{d. Peserta Kurang Berminat untuk Meng- ikuti Kegiatan KP-Ibu}

Kurangnya minat peserta ini karena kesibukan peserta yang menyebabkan tidak adanya waktu untuk mengikuti kegiatan KPIbu terlebih kegiatan KP ibu menyita waktu cukup lama.

"Ya itu tadi, saya terkendala punya anak kecil to. Apalagi anak segitu kan enggak bisa duduk manis terus kita konsentrasi. Ada laundry-an juga, jadi sudah susah." (partisipan 6)

"Kalau aku cuma waktu, enggak cukuplah waktunya. Kan itu enggak cukup setengah jam, satu jam kumpulan kayak gitu. Kan kadang molor-molor juga." (partisipan 5).

Adanya pandangan bahwa ibu sudah bisa merawat anak turut berpengaruh pada minat ibu mengikuti kegiatan KP-lbu. Berikut ungkapan partisipan:

"Kan kesadaran Mbak kalau kayak gitu. Misalnya gini kadang ada yang datang maksudnya kalau ada yang sudah punya anak, ah aku mbiyen wis punya anak, otomatis saya ngrasa sudah bisa. Kan seperti itu." (partisipan 6)

\section{e. Tidak Banyak Memberikan Pengeta- huan Baru pada Peserta}

Pada KP ibu tidak aktif ditemukan tema khusus yakni KP-lbu tidak banyak memberikan pengetahuan baru pada peserta. Pernyataan ini diungkapkan oleh partisipan berdasarkan pengalamannya selama mengikuti kegiatan KP-lbu. Secara umum, kegiatan KP-lbu memang menambah pengetahuan namun pada KP-lbu tidak aktif, partisipan sudah memiliki pengetahuan tersebut sebelum KP-Ibu dibentuk atau telah mendapatkan informasi dari sumber lain. Hal 
ini menyebabkan partisipan di KP-lbu tidak aktif kurang merasakan adanya tambahan pengetahuan baru dari keikutsertaannya di KP-lbu seperti yang diungkapan oleh partisipan berikut:

"Buat aku sih enggak banyak ya Mbak. Soalnya dari dulu sudah banyak yang tahu, banyak yang ngasih tahu. Sama dulu sering browsing itu, jadinya enggak jauh beda." (partisipan 5)

\section{DISKUSI}

Keikutsertaan ibu dalam KP-lbu terbukti memberikan banyak manfaat. Hal ini didukung oleh Handayani, dkk (2013) yang menyebutkan peserta dapat saling berbagi dan berdiskusi seputar pengetahuan menyusui di KP-Ibu dimana selanjutnya pengetahuan ini dapat digunakan untuk memecahkan permasalahan saat menyusui dan secara signifikan mempengaruhi praktek pemberian ASI pada ibu tidak bekerja. Adanya pemberian dukungan sebaya di KP-lbu juga dapat meningkatkan kepercayaan diri untuk menyusui (Hoddinott, dkk, 2010). Keterlibatan peserta dalam KP-lbu dapat disampaikan oleh Ingram (2013) dirasakan oleh ibu sebagai kegiatan yang menyenangkan, mengembirakan, bermanfaat, dan penting bagi seorang ibu karena dapat berkumpul bersama dengan teman sesame.

Terlepas dari manfaat yang muncul, terdapat kendala yang dihadapi baik dari motivator, peserta, dan lingkungan yang menjadikan pelaksanaan KP-lbu belum berjalan optimal. Menurut Cornelia, dkk (2008), motivator memegang peranan dalam membangun suasana diskusi yang akrab, santai, dan nyaman untuk berbagi pengalaman dan pengetahuan. Pelatihan dan mentoring oleh Pembina KP-lbu diperlukan untuk mengembangkan pengetahuan dan keterampilan motivator. Kehadiran peserta, kurangnya minat, dan kurang adanya informasi baru juga turut menjadi faktor yang memengaruhi pelaksanaan KP-Ibu. Penelitian Nugroho (2011), menemukan sebagian besar ibu hamil dan ibu yang mempunyai bayi menganggap kegiatan KP-lbu tidak bermanfaat dan terkesan meremehkan. Keterbaruan informasi yang tidak diperoleh dalam KP-lbu dapat disebabkan sebagian besar ibu hamil $(70 \%)$ telah berupaya mencari informasi tentang pemberian ASI eksklusif (Rinata \& Hamdi, 2015). Kesibukan mengurus rumah tangga dan anak turut menjadi alasan ibu tidak mengikuti kegiatan KP-lbu (Lakhsmi, 2011), padahal tingkat partisipasi yang rendah dapat menurunkan keefektifan program KP-Ibu dalam mendorong ibu mencapai ASI eksklusif (Laela, 2014). Menurut Mother to Mother Support Group Trainer's Manual, waktu pelaksanaan KPIbu sebaiknya tidak mengganggu kegiatan utama peserta seperti memasak, mencuci, pergi ke pasar, bekerja, dll (PATH, 2011). Waktu pelaksanaan KP-Ibu yang bersamaan dengan posyandu menjadikan peserta kurang bisa fokus. Faktor lingkungan dapat mempengaruhi kemampuan untuk mendengarkan [Hargie (2011) dalam Schmitz (2012)].

\section{SIMPULAN}

Berdasarkan hasil penelitian ini mengenai pengalaman keikutsertaan peserta kelompok pendukung ibu dapat disimpulkan kegiatan KP-lbu dapat berjalan aktif dengan karakteristik peserta ibu rumah tangga dengan usia anak kurang dari 2 tahun. Keikutsertaan peserta dalam kegiatan KP-Ibu memberikan manfaat dalam peningkatan pengetahuan dan pemberian ASI eksklusif. Pelaksanaan kegiatan KP-lbu terkendala pada kurangnya kemampuan motivator dalam memandu diskusi, metode yang digunakan kurang menarik, dan lingkungan yang kurang kondusif. Sulitnya 
mengumpulkan peserta, kurangnya minat peserta pada KP ibu, dan tidak banyak pengetahuan baru di KP ibu menjadi faktor penyebab KP ibu menjadi tidak aktif.

Saran bagi motivator KP ibu kegiatan KP ibu sebaiknya ditujukan bagi ibu hamil dan ibu menyusui dengan anak usia kurang dari 2 tahun. Motivator diharapkan bekerjasama dengan kader posyandu untuk pengaturan waktu pelaksanaan KP ibu agar dapat diadakan setelah kegiatan posyandu dan diusahakan tidak menyita waktu lama. Pemberian doorprize dan variasi metode penyampaian informasi dapat digunakan untuk menarik minat peserta. Motivator juga dapat memberikan pertanyaan terbuka atau menunjuk peserta yang masih pasif untuk memberikan kesempatan berbagi pengalaman dengan peserta lain. Pembina KP-lbu juga perlu mengadakan penyegaran topik terbaru dan metode penyampaian informasi yang lebih variatif. Tenaga kesehatan puskesmas atau pembina KP-Ibu diharapkan dapat melakukan kunjungan sekaligus mentoring pada KP-lbu yang masih aktif.

Seiring dengan meningkatnya pemanfaatan smartphone di masyarakat, tenaga kesehatan dapat mempertimbangkan untuk pembentukkan KP-lbu online.

Peneliti selanjutnya diharapkan dapat melakukan penelitian lebih mendalam mengenai minat peserta terhadap kegiatan $\mathrm{KP}$-Ibu dan penelitian mengenai pengaruh mentoring pembina KP-Ibu terhadap keaktifan kegiatan KP-Ibu.

\section{DAFTAR PUSTAKA}

Britton, C., McCormick, F. M., Renfrew, M. J., Wade, A., dan King, S. E. (2007). Support for Breastfeeding Mother (Review). Cochrane Database of Systematic Reviews (1): 1-61
Cornelia, M., E., Turnip, O., M., Wahyuningsih, H., P., Heni, J., G., dan Palupy, R. (2008). Panduan Dasar Pembina Motivator Menyusui. Mercy Corps Indonesia.

Emzir. (2010). Metodologi Penelitian Kualitatif: Analisis Data. Raja Grafindo Persada: Jakarta

Handayani, L., Kosnin, A. M., Jiar, Y. K., dan Solikhah. (2013). Contribution of Knowledge on Breastfeeding among Mothers Who Joined Mother Support Group Program. International Journal of Public Health Science 2(3): 89-92.

Hoddinott, P., Craig, L., Britten, J., dan Mclnnes, R. (2010). A Prospective Study Exploring the Early Infant Feeding Experiences of Parents and Their Significant Others during the First 6 Months of Life: What Would Make A Difference?. NHS Health Scotland: Edinburgh.

Ingram, J. (2013). A Mixed Methods Evaluation of Peer Support in Bristol, UK: Mother', Midwives', and Peer Supporters' Views and the Effects on Breastfeeding. BMC Pregnancy and Childbirth 13(192): 1-10.

Kementerian Kesehatan RI. (2012). Panduan Pembentukan dan Pembinaan Kelompok Pendukung Ibu Menyusui. Jakarta: Direktorat Jenderal Bina Gizi dan Kesehatan Ibu dan Anak.

Laela, N. (2014). Hubungan Tingkat Partisipasi Ibu dalam Kelompok Pendukung Ibu dengan Keberhasilan ASI Eksklusif di Wilayah Kerja Puskesmas Umbulharjo I Yogyakarta (Skripsi). Sekolah Tinggi Ilmu Kesehatan 'Aisyiyah Yogyakarta, Yogyakarta, Indonesia. 
Lakhsmi, T. (2011). Hubungan Kelompok Pendukung Ibu terhadap Perubahan Perilaku Menyusui di Kelurahan Banguntapan, Kecamatan Banguntapan, Kabupaten Bantul di Yogyakarta (Analisa Data Sekunder KPC Healthy Start Yogyakarta Survey 2009-2010) (Tesis). Program Pascasarjana Epidemiologi Komunitas Universitas Indonesia, Jakarta, Indonesia.

Nugroho, A. S. (2011). Peranan Kelompok Pendukung lbu (KP Ibu) dalam Program Peningkatan Capaian ASI Eksklusif (Studi Deskriptif Kualitatif Mengenai Peran KP Ibu dalam Program Peningkatan Capaian ASI Eksklusif di Kelurahan Semanggi, Kecamatan Pasar Kliwon, Kota Surakarta (Skripsi). Fakultas IImu Sosial dan IImu Politik Universitas Sebelas Maret, Surakarta, Indonesia.
PATH. (2011). Mother to Mother Support Group: Trainer's Manual. USAID: USA.

Rinata, E. \& Hamdi, H. P. S. (2015). Persiapan ASI Eksklusif Ibu Hamil di RB Eva Candi Sidoarjo. Midwiferia 1(2): 65-73.

Schmitz, A. (2012). A Primer on Communication Studies. Creative Commons. Retrieved from http://2012books. lardbucket.org/books/a-primer-on communication-studies/s05-02barriers-to effective-listenin.html. 